\title{
Evidence for Early Literacy Intervention: The Impacts of Reading Recovery
}

\author{
Abigail Gray \\ University of Pennsylvania \\ Heather Goldsworthy \\ Henry May \\ Philip Sirinides \\ University of Pennsylvania
}

Follow this and additional works at: https://repository.upenn.edu/cpre_policybriefs

Part of the Educational Assessment, Evaluation, and Research Commons

\section{Recommended Citation}

Gray, Abigail; Goldsworthy, Heather; May, Henry; and Sirinides, Philip. (2017). Evidence for Early Literacy Intervention: The Impacts of Reading Recovery. CPRE Policy Briefs.

Retrieved from https://repository.upenn.edu/cpre_policybriefs/82 


\title{
Evidence for Early Literacy Intervention: The Impacts of Reading Recovery
}

\author{
Abstract \\ Research increasingly links low literacy levels in the early grades with a range of poor outcomes; for \\ instance, students who read below grade level at the end of third grade are about four times less likely \\ than their higher-achieving peers to graduate from high school (Annie E. Casey Foundation, 2010, 2011; \\ Balfanz, Bridgeland, Bruce \& Fox, 2012). In a four-year study, researchers from the Consortium for Policy \\ Research in Education (CPRE) at the University of Pennsylvania and the Center for Research on Education \\ and Social Policy (CRESP) at the University of Delaware examined the effectiveness of Reading \\ Recovery-a widely used 1 st grade literacy program-at helping struggling early readers catch up. The \\ study's findings offer promise for intensive early literacy intervention. \\ Disciplines \\ Education | Educational Assessment, Evaluation, and Research
}




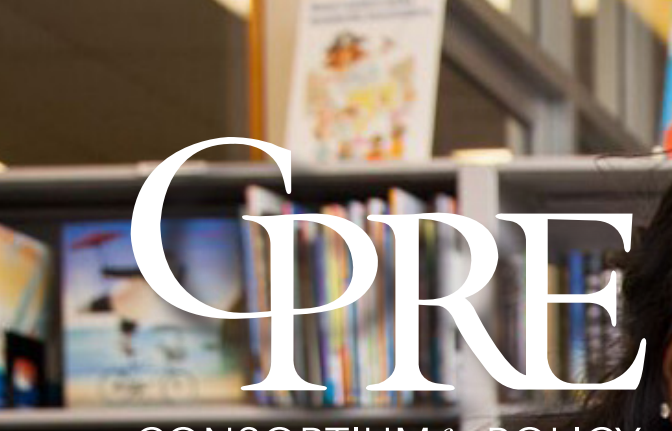

CONSORTIUMfORPOLICY RESEARCHinEDUCATION
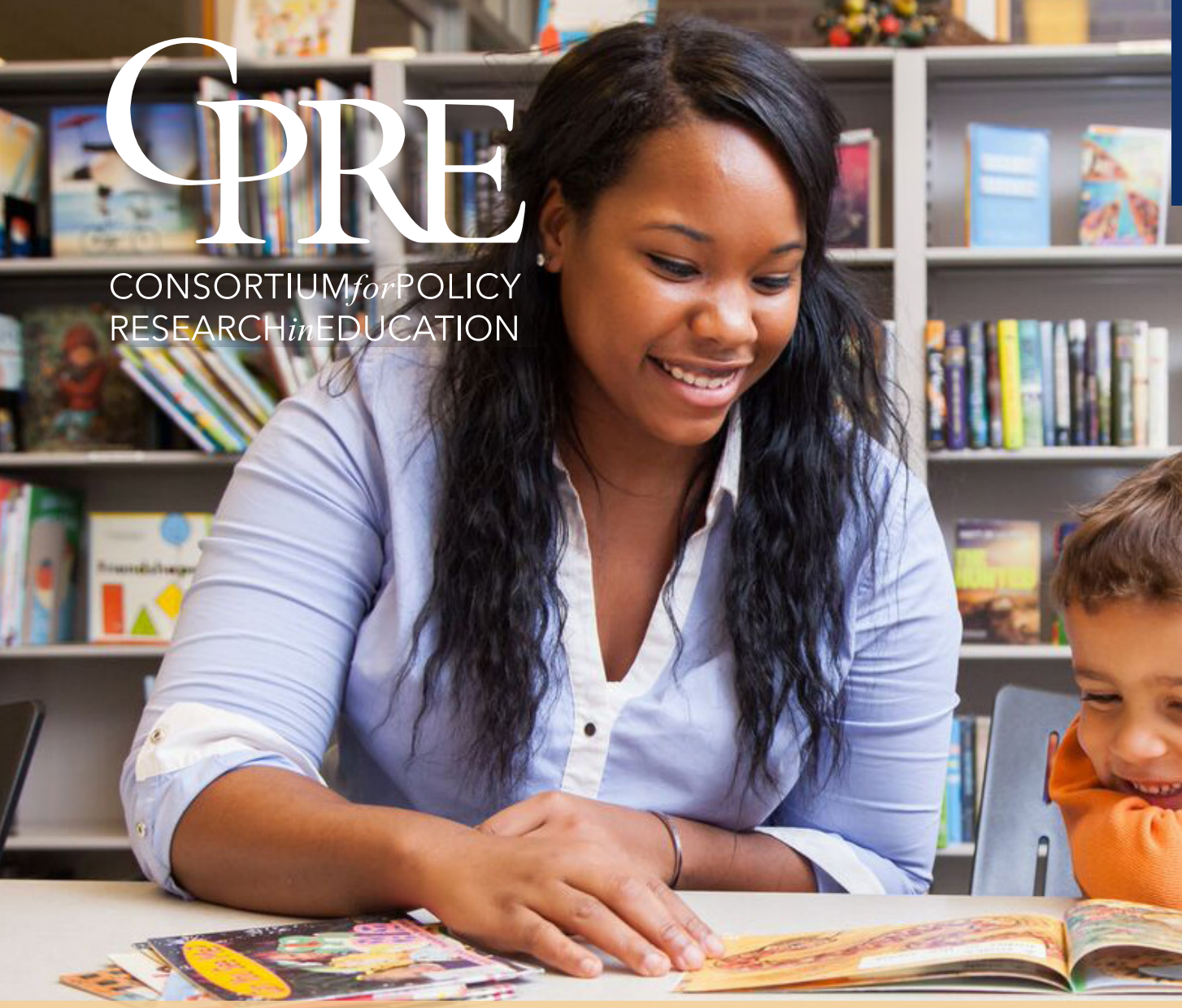

POLICY BRIEF

JANUARY 2017

PB $17-1$

\section{7}

ใดIIII
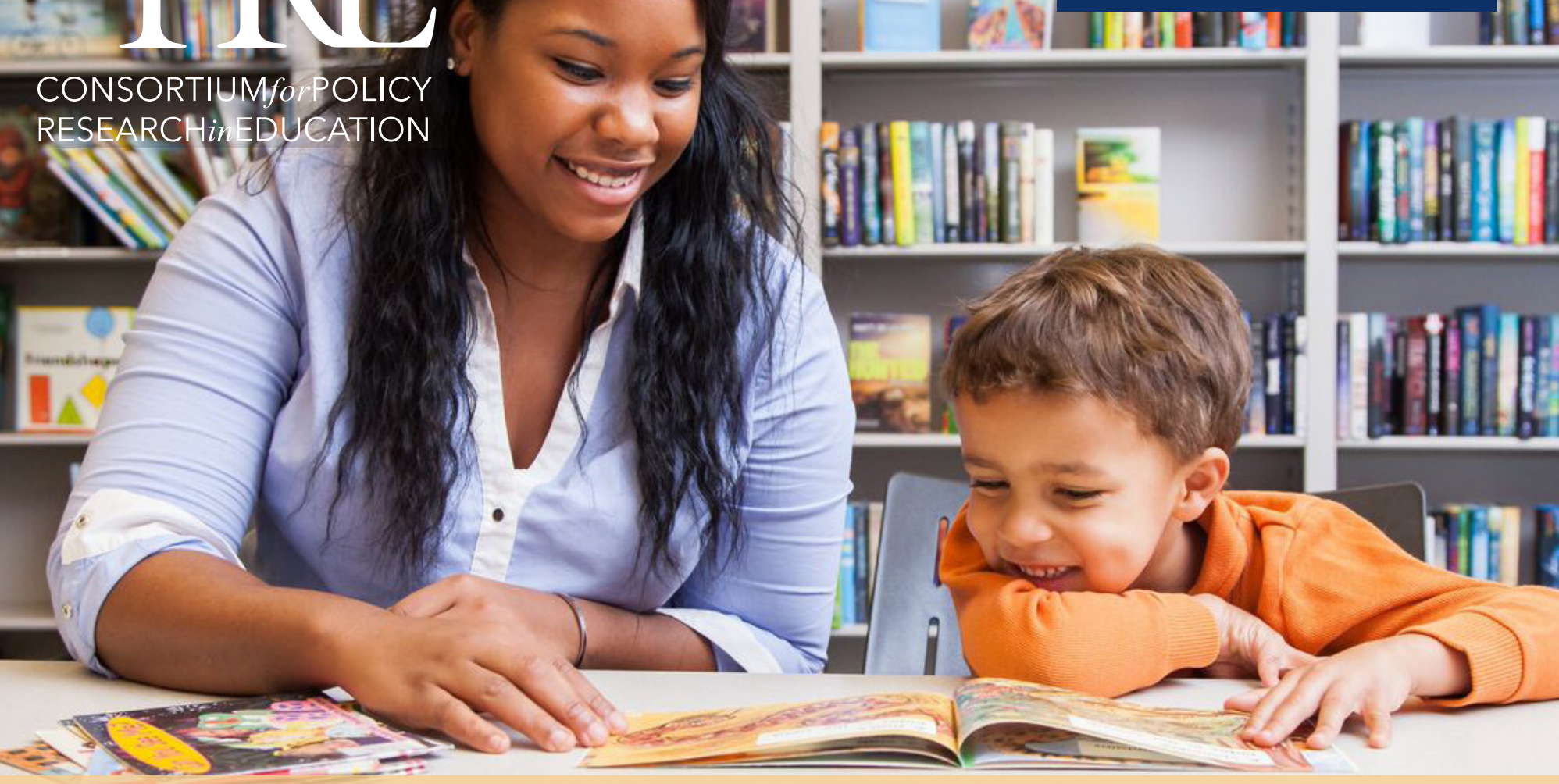

\section{Evidence for Early Literacy Intervention:}

\section{The Impacts of Reading Recovery}

\section{Introduction}

Research increasingly links low literacy levels in the early grades with a range of poor outcomes; for instance, students who read below grade level at the end of third grade are about four times less likely than their higher-achieving peers to graduate from high school (Annie E. Casey Foundation, 2010, 2011; Balfanz, Bridgeland, Bruce \& Fox, 2012). In a four-year study, researchers from the Consortium for Policy Research in Education (CPRE) at the University of Pennsylvania and the Center for Research on Education and Social Policy (CRESP) at the University of Delaware examined the effectiveness of Reading Recovery-a widely used 1st grade literacy program-at helping struggling early readers catch up. The study's findings offer promise for intensive early literacy intervention.

Reading Recovery is a literacy intervention for 1st graders. It was developed in the 1970s by Marie Clay, a New Zealand psychologist and educator (Clay, 1991; 2005), and has become one of the most widely used reading programs in the world.

Reading Recovery consists of a 12- to 20 -week series of individual, daily, 30-minute lessons provided by a specially trained teacher. The program aims to help students develop self-directed literacy strategies.

\section{Henry May \\ Philip Sirinides \\ Abigail Gray}

Heather Goldsworthy

Penn GSE

Center for Research in Education and Policy 
In one of the largest randomized controlled trials ever conducted on an instructional program, CPRE and CRESP analyzed data from nearly 7,000 students between 2011 and 2015. The evaluation was funded by a 2010 Investing in Innovation (i3) grant to The Ohio State University (OSU) - the seat of Reading Recovery in the United States-from the U.S. Department of Education's Office of Innovation and Improvement. The grant funded the expansion of Reading Recovery to nearly 70,000 additional students, and allocated funds for a rigorous, multi-year independent evaluation.

\section{What the evaluation revealed}

\section{Key findings from the randomized trial component of the CPRE/CRESP evaluation of Reading Recovery include the following:}

- Students who received Reading Recovery performed significantly better on a standardized literary assessment at the end of the intervention than those who did not.

- Schools that had the lowest average student achievement tended to have the largest treatment effects, suggesting that low-achieving students benefit most from the program.

- English Language Learners and students in rural schools realized similar benefits to students overall.

- There was considerable variation from school to school in the size of Reading Recovery's treatment effects.

- Findings from an exploratory study of long-term impacts on 3rd grade reading scores were inconclusive as a result of the small sample available for the analysis-most students in the study had not yet reached Grade 3. Long-term impacts will be addressed in a follow-up study.

\section{The implementation study component of the evaluation produced a number of insights about schools' use of Reading Recovery. Among these are:}

- Some Reading Recovery lessons are stronger than others, and differences in lesson quality result from both teacher and school factors.

- Schools integrate Reading Recovery in various ways. Those with high levels of principal leadership and communication about the program realize the greatest benefits.

To implement the evaluation, CPRE and CRESP randomly selected a group of schools from those participating in the i3-funded scale-up of Reading Recovery in each of four years (2011-2015). In the selected schools, teachers used assessments to identify the eight lowest-achieving 1st-grade students in the school. Four of those eight were randomly assigned to receive Reading Recovery lessons in addition to regular classroom instruction in the first half of the school year (the treatment group). The other four served as the control group, receiving regular classroom instruction and any other interventions their schools typically provide to struggling lst grade readers. The control group students were eligible to receive Reading Recovery later in the year. 
Students in both treatment and control groups were assessed using the lowa Test of Basic Skills (ITBS) Reading Total subtest; ITBS subtests in Comprehension and Reading Words; and the Observation Survey of Early Literacy Achievement (OS).

The i3 evaluation also included an in-depth study of Reading Recovery's implementation in schools in the i3 scale-up. This study included hundreds of interviews with implementers, including school- and districtlevel administrators; instructional observations; and 23 field-based case studies that examined how particular schools incorporated Reading Recovery.

\section{Just how big are the impacts of Reading Recovery?}

The i3 evaluation found that, compared with students in the control group, 1st graders who were randomly assigned to Reading Recovery scored an average of 3.41 points higher on the ITBS Reading Total scale, 3.57 points higher on the ITBS Reading Words scale, and 3.90 points higher on the ITBS Comprehension scale at the end of the intervention. The effect sizes represented by these differences range from 0.30 to 0.42 standard deviations.

These treatment effects can be interpreted in several ways. For instance, they can be translated to months of student learning. As Figure 1 illustrates, students who received Reading Recovery made between one and two months of additional growth during the roughly five-month timeframe of the experiment as compared with the national average from the ITBS norming sample. This growth rate is more than $130 \%$ of the typical average growth rate for 1st grade students.

Figure 1: Average months of learning for September through January of 1st grade

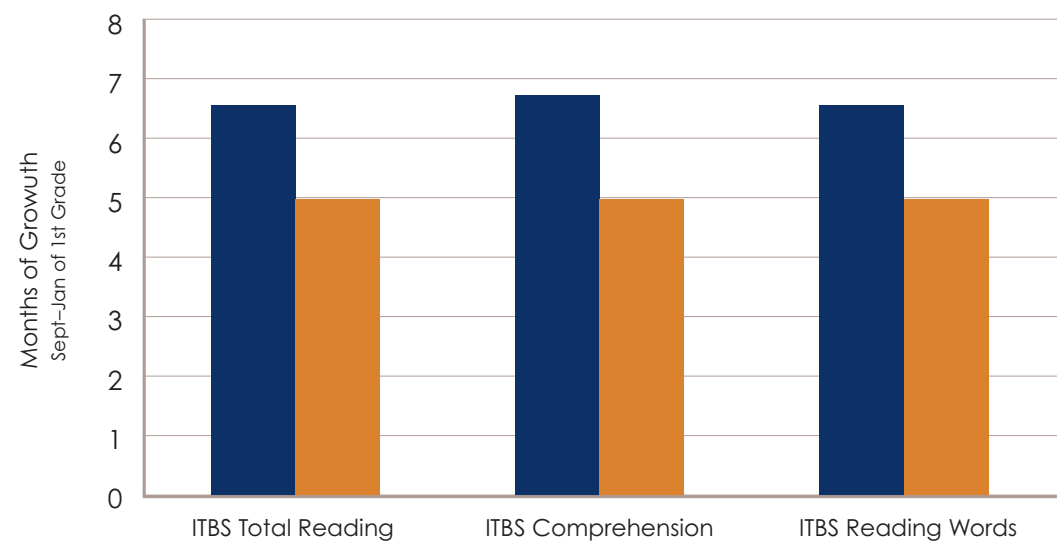

i3 Treatment Group Average 


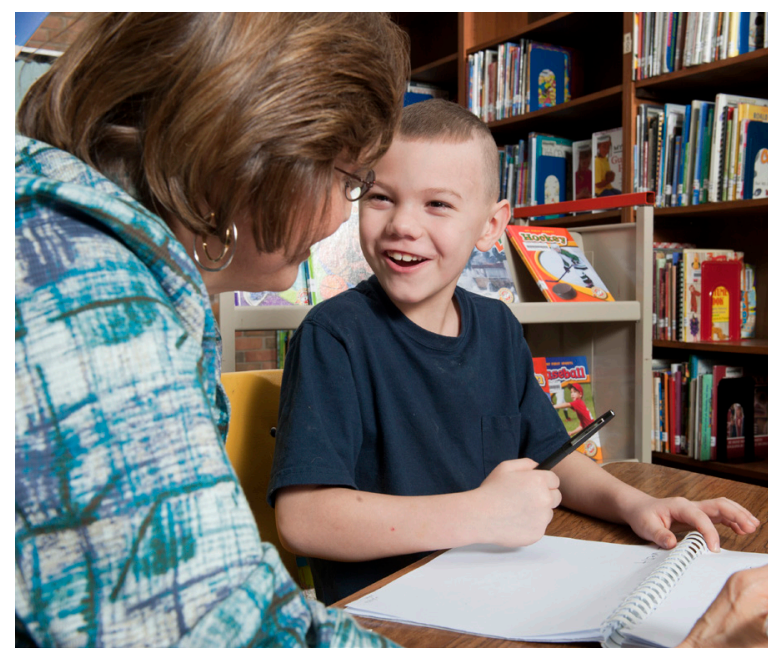

The effect sizes for Reading Recovery can also be compared to those of other instructional programs. A study by Lipsey et al. (2012) presents mean effect sizes for different types of educational interventions. For instructional programs like Reading Recovery, they report average effect sizes (using Cohen's d) of 0.13. The total standardized effect size (using Cohen's d) for Reading Recovery was 0.37. As Figure 2 shows, this indicates that Reading Recovery's effects were 2.8 times greater than the reading outcomes of other instructional interventions. Similarly, the impacts of Reading Recovery were 3.5 times larger than the average effects of Title I programs reviewed by Borman and D'Agostino (1996).

Figure 2: Average treatment effects for elementary instructional programs

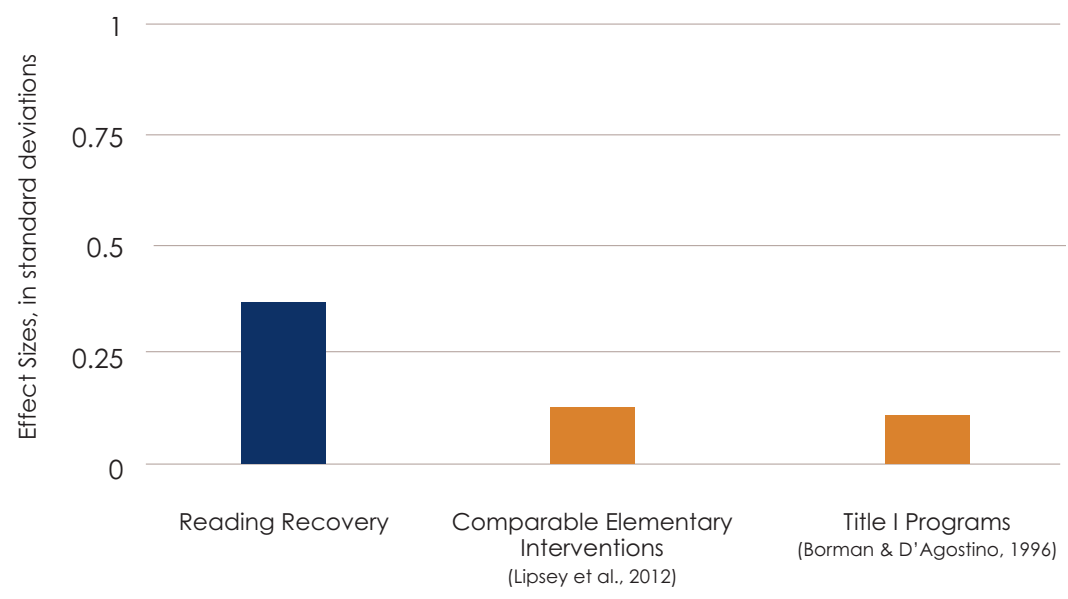

\section{Key Takeaways}

The CPRE/CRESP evaluation of Reading Recovery was one of the largest and most rigorous studies of an educational intervention ever conducted. It found treatment effects that are among the largest observed from an instructional program. The study therefore offers strong evidence of the impact of Reading Recovery on the reading skill of struggling 1st graders. In addition, it demonstrates the feasibility of effectively scaling up an intervention.

The study also revealed that some schools' Reading Recovery programs are more effective than others, and that differences in teachers' instruction and in schools' embrace of the program may contribute to variation in school-level impacts.

The complete final report from the i3 evaluation of Reading Recovery is available for download at www.cpre.org/ readingrecovery. 


\section{The making of a Reading Recovery teacher}

Reading Recovery takes a unique and intensive approach to teacher training. Each first-year Reading Recovery teacher participates in a year-long graduate-level course that grounds their day-to-day teaching experiences in Reading Recovery theory and techniques.

The course is taught by a highly trained literacy expert who is typically an experienced Reading Recovery teacher. In addition to teaching the weekly class, the instructor provides side-by-side coaching support to teachers in training as they navigate their first year, and reduced but ongoing support in successive years.

One distinctive feature of Reading Recovery training is behind-theglass instruction. In a behind-the-glass session, a teacher conducts a real-time lesson with a student behind a two-way mirror, while a teacher leader and other teachers observe. After the session, observers offer detailed feedback intended to help refine the teacher's instruction.

Reading Recovery teachers' near-unanimous praise for the training process was a key finding early in the i3 study. Comments like the following, from a first-year Reading Recovery teacher, were common: "I would say I learned more in this one class than I did in my entire master's program to become a reading specialist."

\section{References}

Balfanz, R., Bridgeland, R. M., Bruce, M., \& Hornig Fox, J. (2012). Building a grad nation: Progress and challenge in ending the high school drop out epidemic. Annual Update 2012. John's Hopkins University America's Promise Alliance.

Borman, G. D., \& D'Agostino, J. V. (1996). Title I and student achievement: A meta-analysis of federal evaluation results. Educational Evaluation and Policy Analysis, 18(4), 309-326.

Clay, M. M. (1991). Becoming literate: The construction of inner control. Portsmouth, NH: Heinemann.

Clay, M. M. (2005). Literacy Lessons Designed for Individuals: Why? when? and how?. Portsmouth, NH: Heinemann.

Hernandez, D. J. (2012). Double jeopardy: How third-grade reading skills and poverty influence high school graduation. The Annie. E. Casey Foundation. Baltimore, MD.

Lipsey, M. W., Puzio, K., Yun, C., Hebert, M. A., Steinka-Fry, K., Cole, M. W., ... \& Busick, M. D. (2012). Translating the statistical representation of the effects of education interventions into more readily interpretable forms. Washington DC: U.S. Department of Education, National Center for Special Education Research.

May, H., Gray, A., Sirinides, P., Goldsworthy, H., Armijo, M., Sam, C., Gillespie, J.N., \& Tognatta, N. (2015). Year one results from the multisite randomized evaluation of the i3 scale-up of Reading Recovery. American Educational Research Journal, 52(3), 547-581.

May, H., Gray, A., Gillespie, J. N., Sirinides, P., Sam, C., Goldsworthy, H., Armijo, M. \& Tognatta, N. (2013). Evaluation of the i3 Scale-up of Reading Recovery: Year one report, 2011-12. Philadelphia: Consortium for Policy Research in Education. 


\section{Suggested Citation}

May, H., Sirinides, P., Gray, A., \& Goldsworthy, H. (2016). Evidence for Early Literacy Intervention: The Impacts of Reading Recovery (PR-15-5)Philadelphia, PA: Consortium for Policy Research in Education.

This brief was derived from the full report:

May, H., Sirinides, P., Gray, A., \& Goldsworthy, H. (2016). Reading Recovery: An Evaluation of the Four-Year i3 Scale-Up. Philadelphia:

Consortium for Policy Research in Education.

Copyright (C) 2017 by the Constortium for Policy Research in Education. All rights reserved.

\section{Questions? Find More Info}

Contact CPRE researcher Abigail Gray at grayab@upenn.edu or for general questions, email: cpre@upenn.edu.

\section{Stay connected and join the conversation online!}

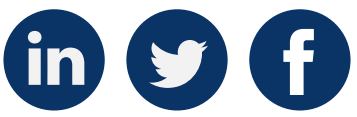

Consortium for Policy Research in Education @CPREresearch | CPRE.ORG

Subscribe to CPRE Insights eNewsletter: bit.ly/CPREinsights

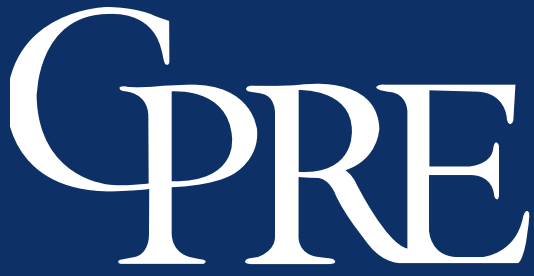

CONSORTIUMforPOLICY RESEARCHinEDUCATION

The Consortium for Policy Research in Education (CPRE) brings together education experts from renowned research institutions to contribute new knowledge that informs PreK-16 education policy and practice. Our work is peer-reviewed and open-access. Our institutions include:

University of Pennsylvania

Teachers College, Columbia University

Harvard University

Stanford University

University of Michigan

University of Wisconsin-Madison

Northwestern University

The Consortium for Policy Research in Education (CPRE) is headquartered at the Graduate School of Education at University of Pennsylvania.

For more information, visit: cpre.org. 